ArtefaCToS. Revista de estudios de la ciencia y la tecnología

eISSN: 1989-3612

Vol. 8, No. 2 (2019), 2. ${ }^{a}$ Época, 161-178

DOI: http://dx.doi.org/10.14201/art201982161178

\title{
John Dewey: hacia una historia natural de la lógica
}

\author{
John Dewey: Towards a Natural History of Logic
}

\author{
Ángel Manuel FAERNA \\ Universidad de Castilla la Mancha, España \\ angel.faerna@uclm.es
}

Recibido: 06/01/2019. Revisado: 25/05/2019. Aceptado: 25/05/2019

\section{Resumen}

La filosofía de la lógica de Dewey representa un intento de conectar las prácticas inferenciales humanas con el medio natural y cultural en el que han evolucionado en tanto que métodos de investigación. En esta interpretación, las leyes lógicas no tienen un fundamento psicológico, pues son de carácter prescriptivo, pero su objetividad no remite tampoco a un ámbito de normas últimas, independientes de todo interés humano. Este trabajo intenta clarificar la concepción pragmatista y naturalista que Dewey tiene de la lógica comparándola, por un lado, con la crítica de Frege al psicologismo y, por otro, con el ataque de Brandom al instrumentalismo y su defensa de un "excepcionalismo normativo" en relación con nuestras prácticas inferenciales.

Palabras clave: instrumentalismo; naturalismo; normatividad; pragmatismo; psicologismo.

\begin{abstract}
Dewey's philosophy of logic is an attempt to connect inferential practices to the natural and cultural environment wherein they evolve as methods of inquiry. In Dewey's view, the laws of logic are not psychologically grounded for they are prescriptive, but their objective nature does not reflect an order of norms which is ultimate and independent of human interests. This paper intends to clarify Dewey's pragmatist, naturalist conception of logic by contrasting it with Frege's criticism of psychologism, on one hand, and with Brandom's anti-instrumentalist, "normative excepcionalist" explanation of inferential practices, on the other.
\end{abstract}

Keywords: instrumentalism; naturalism; normativity; pragmatism; psychologism. 
Ángel Manuel Faerna

John Dewey: hacia una historia natural de la lógica

\section{La Logic de Dewey, 80 años después}

John Dewey publicó en 1938 Logic: The Theory of Inquiry, un grueso volumen de más de 500 páginas que le llevó trece años redactar y del que él mismo dice en el Prefacio que representa la culminación de casi cuarenta años de trabajo. ${ }^{1}$ Cuando aún estaba preparándolo, le confesó en una carta a su amigo Albert Barnes, el célebre filántropo y coleccionista de arte, que aquel libro era su "primer y último amor". El autor tenía por entonces 75 años y quizá lo viera como una especie de testamento filosófico; poco podía imaginar que viviría hasta los 93 y todavía le daría tiempo a publicar varios títulos importantes más.

Lo menos que puede decirse de la Logic de Dewey es que, como tratado de lógica, resulta absolutamente singular, no solo a ojos del lector actual sino ya en sus propios días. A Bertrand Russell le pareció una obra monumental, con el único defecto de que no contenía ni una sola palabra de lógica. Para empezar, carece de axiomas y teoremas y está escrita en prosa, sin aparato formal alguno; ${ }^{2}$ en cambio, habla de prehistoria y de historia, de biología, de antropología, de tecnología, de métodos científicos... Es verdad que contiene discusiones técnicas sobre las teorías del significado y de la lógica de su tiempo, incluidas las de los Principia Mathematica, pero a Russell el libro no le escandalizó porque cuestionara sus ideas sino porque realmente situaba la disciplina en un contexto para él insólito y completamente extemporáneo. El lector actual obtendrá una impresión parecida, pero con la diferencia de que su juicio sobre la luz que, entre tanto, han aportado a la disciplina los desarrollos del siglo XX puede no ser tan favorable como el que se auguraba:

A lo largo del siglo XX, la lógica (simbólica, matemática, o como se quiera llamar) se ha convertido en una ciencia desarrollada que avanza a buen ritmo y en diferentes direcciones, ganando de manera constante en amplitud y en sofisticación. Eso es verdad, avanza la sofisticación técnica, pero no avanza ni el análisis de sus conceptos fundamentales ni la comprensión de su objetivo [...] El resultado es un

\footnotetext{
${ }^{1}$ Allí menciona como "primera presentación" de sus ideas sobre la naturaleza de la lógica los Studies in Logical Theory, un volumen colectivo que editó en 1903 y que recogía trabajos suyos y de otros siete profesores de la Universidad de Chicago; en sus Essays in Experimental Logic, de 1916, las "amplió un poco", pero antes las había "resumido brevemente" para aplicarlas a la educación en How We Think, de 1910 (Dewey, 1989). Véase el Prefacio a Dewey 1991, 3. Existe una vieja traducción al castellano de Eugenio Ímaz (Dewey, 1950), meritoria pero bastante defectuosa técnicamente. Aquí citaremos por la edición original y con el sistema acostumbrado para los escritos de Dewey, esto es, con las iniciales de la serie correspondiente en sus obras completas, seguidas del volumen y el número de página: en este caso, LW 12, 3.

${ }^{2}$ De lo cual Dewey da cuenta también en el Prefacio, consciente de que esa circunstancia le iba a granjear algunas críticas. Según él, el tratamiento simbólico exige "el establecimiento previo de ideas válidas de los conceptos y relaciones que se simbolizan", que es uno de los objetivos del libro; "si no se cumple este requisito, la simbolización formal se limitará a perpetuar errores existentes (como tan a menudo sucede hoy), a la vez que los refuerza aparentando darles prestigio científico" (LW 12, 4).
} 
conjunto de estudios, sistemas, problemas y soluciones, posiblemente complejas y elegantes pero sin relevancia real ni para el avance de la ciencia ni para la comprensión de las actividades inferenciales de los seres humanos de carne y hueso. (Frápolli, 2017, 3)

En efecto, la pregunta por la naturaleza de la lógica — formulada del modo más simple e ingenuo posible: cuál es el estatuto de las leyes lógicas y de qué tratan exactamente- parece estancada casi en el mismo punto en que la heredamos del siglo XIX, cuando los avances revolucionarios en el campo la hicieron saltar al primer plano. La respuesta de Dewey a esa pregunta es relativamente fácil de sintetizar: la lógica no sería otra cosa que una herramienta para investigar (la misma idea que tenía Aristóteles, por cierto). Como toda herramienta, es un producto del ingenio humano, un dispositivo que integra operaciones de muy distinto tipo, unos materiales y otras ideales, todas ellas referidas a lo que existe o puede existir efectivamente y no a lo meramente pensado. ${ }^{3}$ También como toda herramienta, responde a condiciones específicas que vienen impuestas por el entorno natural y la vida social, conecta con necesidades igualmente específicas y se refina y perfecciona con el uso. Desde una concepción así, el contexto en que Dewey decide colocar su teoría de la lógica puede que no resulte ya tan extemporáneo, aunque nos siga pareciendo insólito. Que además ayude a analizar correctamente los conceptos lógicos fundamentales y a comprender mejor su objetivo es algo para lo que Dewey se limitó a reclamar el beneficio de la duda: "si se quiere evitar el puro y simple dogmatismo, cualquier hipótesis, por extraña que sea, debe tener una oportunidad justa y ser juzgada por sus resultados" (LW, 12, 12).

En cuanto a la actividad misma de investigar, que es para lo que la herramienta está concebida y fabricada, es sabido que Dewey la entendía como una actividad de resolución de problemas, algo cuyo patrón básico puede reconocerse ya en la conducta adaptativa de cualquier organismo vivo, pero que adquiere autonomía y una cierta dinámica propia merced a la incorporación de la dimensión lingüística, de las habilidades simbólicas y del universo de reglas a que da lugar la conducta inteligente y reflexiva:

La transformación de la conducta orgánica en conducta intelectual marcada por propiedades lógicas es fruto del hecho de que los individuos viven en un medio cultural. [...] El lenguaje ocupa un lugar especialmente significativo y ejerce una función especialmente importante en el complejo que forma el entorno cultural. Él mismo es una institución cultural y, desde un cierto punto de vista, no es

\footnotetext{
3“Los métodos de investigación son operaciones realizadas o que hay que realizar. Las formas lógicas son las condiciones que la investigación debe cumplir qua investigación. [...]Hay operaciones que se realizan sobre el material existente y con él, como en la observación experimental, y hay operaciones que se realizan sobre símbolos y con ellos. Pero, incluso en el segundo caso, 'operación' debe tomarse en el sentido más literal posible [...]. El así llamado elemento 'mental' de las operaciones de ambos tipos debe definirse en términos de condiciones y consecuencias existenciales, no al revés" (LW, 12, 22).
} 
más que una entre otras muchas instituciones. Pero [...] tiene su propia estructura distintiva, la cual es susceptible de abstracción como forma. Esa estructura, una vez abstraída como forma, tuvo históricamente una influencia decisiva en la formulación de la teoría lógica. [...] Me ceñiré a la función especial del lenguaje a la hora de producir la transformación de lo biológico en lo intelectual y en lo potencialmente lógico. (LW, 12, 51)

Por eso no es descabellado decir que la intención de Dewey en este libro era escribir una historia natural de la lógica (donde "natural" no se opone a "cultural" en sentido antropológico, sino que evidentemente lo incluye). De hecho, esa es la etiqueta que le adjudicó Charles $S$. Peirce, el lógico con el que Dewey reconoce más deudas a lo largo de la obra. Y, sin embargo, Peirce no la usó como un elogio precisamente:

Usted propone sustituir la Ciencia Normativa que, a mi juicio, es lo que más se necesita en estos tiempos nuestros, por una 'Historia Natural' del pensamiento o de la experiencia. Lejos de mí hacer nada por impedir que un hombre descubra cualquier verdad que esté en vías de descubrir, pero no creo que nada parecido a una historia natural pueda cubrir la tremenda necesidad que detecto al ver qué horroroso desperdicio de tiempo, de energías y de pensamientos está causando el que los hombres no comprendan la teoría de la inferencia. (Peirce, 1904) ${ }^{4}$

Peirce no se refería a la Logic de 1938, pues no vivió para leerla, sino a los Studies in Logical Theory de 1903, donde Dewey había presentado sus primeras ideas al respecto. Cabría preguntarse si esa impresión suya de que Dewey quería sustituir una ciencia normativa por otra histórica se habría mantenido de haber conocido las mismas ideas en su formulación más madura y completa. Cabría preguntarse también si no sería este comentario epistolar de Peirce ${ }^{5}$ lo que llevó a Dewey a incluir entre las seis implicaciones más destacadas de su teoría la de que "las formas lógicas tienen el carácter de postulados", en el sentido de que prescriben o estipulan las condiciones que debe satisfacer la investigación' despejando así cualquier sospecha de que la teoría pretendiera cuestionar el valor normativo de la lógica. ${ }^{6}$ Aunque mi objetivo aquí no es analizar parecidos y diferencias entre la concepción de la lógica de Peirce y la de Dewey, ${ }^{7}$ sino hacer algunas observaciones sobre el interés intrínseco de esta última, hay dos matices en las palabras de Peirce que tienden a pasarse por alto y que aportan una clave importante respecto de ese posible interés intrínseco.

${ }^{4}$ Carta de Peirce a Dewey de 9 de junio de 1904; cit. en Colapietro (2002).

${ }^{5}$ Que, por cierto, no repitió luego en la reseña del libro que escribió para Nation el 15 de septiembre de 1904 (cf. Ketner y Cook, 1979).

${ }^{6} \mathrm{LW}, 12,23$; sobre el carácter normativo de las formas lógicas, véase todo este epígrafe, pp. 23-26. ${ }^{7}$ Para ese análisis, véase Hickman (1986), y la réplica de Colapietro (2002) a Hickman. 
En primer lugar, Peirce no niega que la idea de una "historia natural del pensamiento" - de cómo el pensar lógico se desarrolla a partir de condiciones naturales (y culturales) únicamente- pueda ponernos en el camino de descubrir alguna verdad importante; es decir, no la considera una tarea condenada al fracaso desde el principio, como seguramente habrían opinado la mayoría de los lógicos pero no uno que, como él, había elevado las categorías de evolución y continuidad a rango metafísico. En segundo lugar, y más relevante, su escepticismo se refiere solo a la utilidad y la oportunidad de la empresa de Dewey, es decir, a que pudiera ser lo que en ese momento se necesitaba para hacer comprender a los hombres la teoría de la inferencia. Por consiguiente, lo que habría que empezar por preguntarse es: ¿qué se necesitaba en aquel momento?, ¿por qué "nada parecido a una historia natural" podía cubrir esa "tremenda necesidad"?, y ¿nuestra actual incapacidad de "comprender las actividades inferenciales de los seres humanos" responde a las mismas carencias y sigue haciendo inútil e inoportuna la empresa de Dewey, o la situación se ha invertido y hoy esa empresa puede ser más oportuna y más útil?

\section{El valor de lo lógico}

La articulación entre lo descriptivo y lo normativo es un problema al que ninguna concepción de la racionalidad puede escapar, y uno de los méritos que se le pueden reconocer imparcialmente al pragmatismo es haber concentrado el foco de atención sobre él, ya sea en términos generales o tal como se manifiesta en debates filosóficos más acotados, empezando por los que tienen que ver con la ciencia y con el conocimiento mismo. A ese respecto, Dewey estaba escribiendo en un clima teórico en el que progresaba rápidamente el positivismo lógico, para el cual dicha articulación se resolvía en una dicotomía tajante entre "hechos" y "valores" que servía justamente para demarcar el discurso lógicamente reglamentado, es decir, cognitivo y científico, de las manifestaciones meramente expresivas de emociones y deseos subjetivos, con los juicios morales como ejemplo paradigmático. Como acababa de sentenciar Alfred Ayer en Lenguaje, verdad y lógica:

La presencia de un símbolo ético en una proposición no añade nada a su contenido fáctico. Así, si le digo a alguien 'hiciste mal robando ese dinero', no estoy enunciando algo más que si le hubiera dicho sencillamente 'robaste ese dinero'. $\mathrm{Al}$ añadir que esa acción está mal no estoy haciendo otro enunciado más sobre ella, simplemente estoy mostrando mi desaprobación moral hacia ella. Es como si hubiera pronunciado 'robaste ese dinero' en un tono particular de horror o lo hubiera escrito añadiéndole ciertos signos de exclamación especiales. El tono o los signos de exclamación [...] solo sirven para hacer ver que [la expresión de la oración] va acompañada de ciertos sentimientos en el hablante. (Ayer, 1983, 142) ${ }^{8}$

${ }^{8}$ El libro de Ayer apareció en 1936, dos años antes que la Logic de Dewey; justo a continuación de esta, en 1939, Dewey publicó su Teoría de la valoración en el órgano oficial de los neopositivistas, 
Visto desde hoy, es difícil entender que una posición tan artificial como esta llegara a gozar de crédito filosófico por algún tiempo. Equiparar semánticamente un juicio, sea o no de valor, a una interjección es un despropósito evidente que merecería ser pronunciado él mismo en tono de horror y subrayado con exclamaciones. Los juicios, a diferencia de las interjecciones, se pueden contradecir, esa es una de las reglas que los caracterizan como emisión lingüística y en ello se funda todo un conjunto de prácticas de los hablantes, como, por ejemplo, la de que sea pertinente dar o pedir su justificación. Esto es así con independencia del contenido emitido, pues tiene que ver exclusivamente con la naturaleza de los actos de habla y las situaciones en que nos colocan, no con ninguna teoría sobre el estatuto más o menos cognitivo de los hechos y los valores. Tales teorías tienen su propio espacio de discusión, pero desde luego no es el de la pragmática lingüística; que robaste ese dinero y que estuvo mal que lo hicieras son dos juicios netamente distintos, pensemos lo que pensemos sobre sus respectivos modos de justificación, y cuando Ayer los iguala hace desaparecer sin darse cuenta el motivo de la discusión que él mismo propone, a saber, si las justificaciones que cabe dar o pedir para un juicio de valor tienen base cognitiva - como la tienen las del juicio fáctico de que has cometido un robo- o se mueven en un espacio de razones enteramente diferente.

El emotivismo, que en su versión no lingüística hunde sus raíces en el empirismo y el positivismo clásicos, dejó una impronta profunda en la "concepción heredada" dentro de la filosofía de la ciencia, es decir, la teoría del método científico acunada en el marco del empirismo lógico. Los filósofos de la ciencia siguieron pensando durante bastante tiempo que un juicio de valor tenía que ser algo necesariamente relacionado con los gustos y preferencias de quien lo hacía, algo intrínsecamente "subjetivo" y, por tanto, una cosa rigurosamente prohibida al científico. Que la tarea de la ciencia es entender los "hechos" manteniéndolos escrupulosamente separados de los "valores" se tomaba poco menos que por una verdad evidente en sí misma.

Hoy esta situación ha cambiado. La epistemología en general, y la metodología de la ciencia en particular, reconocen actualmente que los valores (siquiera sea los "epistémicos") son consustanciales al discurso del conocimiento, para empezar porque el término "conocimiento" posee ya en su significado mismo un componente valorativo o normativo inequívoco. Decir de un determinado contenido que es un "caso de conocimiento" es asignarle un valor y no simplemente constatar que deriva de tales o cuales operaciones y procedimientos previamente descritos. Prueba de ello es que incurriríamos en una contradicción performativa si dijéramos de una afirmación que es conocimiento $\mathrm{y}$, al mismo tiempo, negáramos que es fidedigna o digna de ser creída. La expresión "digna de ser creída"

La Enciclopedia Universal de la Ciencia Unificada, como réplica al emotivismo moral (LW, 13, 189-251). Para una contextualización de esta polémica, véase el Estudio introductorio a Dewey (2008, 11-52). 
no tiene sentido figurado, asigna una dignidad o un mérito a la afirmación, del mismo modo que la expresión "digna de ser realizada" asigna un mérito a una acción. Esto, por cierto, era exactamente lo que trataba de decir William James, para escándalo de sus coetáneos, cuando hablaba de la verdad como un "título honorífico" que le otorgamos a ciertas creencias.

Eso no significa, obviamente, que el valor o dignidad en cuestión vaya a depender de los gustos o preferencias de nadie en particular. Salvo para las posiciones más intransigentemente intuicionistas en epistemología, la creencia verdadera se ha vinculado siempre a la ejecución de ciertas operaciones y la observancia de ciertos procedimientos — al respeto, en suma, de principios generales de orden lógico y metodológico - a la hora de concederle ese título. O, si no la creencia verdadera, sí al menos la creencia justificada. Es cierto que, para muchos, tener suficiente justificación para llamar verdadera a una creencia (esto es, para creerla) y que tal creencia sea verdadera son todavía dos cosas distintas. En cierto modo, la situación recuerda a aquella que planteaba G. E. Moore respecto del uso del adjetivo "bueno" en sentido moral: aun cuando llegáramos a constatar, por ejemplo, que todo lo que produce placer resulta ser siempre bueno, seguiría teniendo sentido preguntarse si algo que es placentero es bueno también; pero si la bondad y el placer (o cualquier otra propiedad "natural" por la que intentemos definirla) fueran lo mismo - argüía Moore-, entonces todo lo que estaríamos preguntando es si lo bueno es bueno, lo cual no parece el caso.

Moore llegó a reconocer ańos después que este argumento en pro del carácter simple, no analizable y no natural de la propiedad "bueno" era falaz porque encerraba una petición de principio, aunque de todas formas él siguiera pensando que se trataba de una propiedad de ese tipo. ${ }^{9}$ Con el adjetivo "verdadero" ocurre algo parecido: del hecho de que siempre podamos preguntar todavía si es verdadera una creencia para la que ahora tenemos justificación no se sigue que su justificación y su verdad sean cosas distintas e independientes, salvo que partamos del supuesto de que lo que significa que sea verdadera ya ha quedado determinado al margen de la controversia misma. Aun así, se puede seguir pensando que la verdad y la justificación son dos cosas distintas - como Moore siguió pensando que la bondad era una propiedad distinta de cualquier propiedad natural- y que "verdadero" también es un concepto primitivo e indefinible, pero eso es solo reafirmarse en una tesis, no reforzarla con ningún argumento.

De todos modos, la cuestión de cuál es la diferencia, si es que la hay, entre aquello que tenemos las mejores razones para afirmar y la Verdad con mayúsculas entra de lleno en el territorio de la metafísica, un campo que los positivistas lógi-

\footnotetext{
9"En los Principia [Ethica] dije y me propuse probar que 'bueno' era indefinible (y creo que muchas veces, aunque quizá no siempre, usé esta palabra para decir lo mismo que con 'valioso por sí mismo'). Pero, ciertamente, todas las supuestas pruebas eran falaces. Ninguna de ellas podía probar que 'valioso por sí mismo' es indefinible. Pienso que tal vez sea indefinible: no lo sé. Pero sigo considerando muy probable que sea indefinible" (Moore, 1972, 127).
} 
cos desdeñaban. Y aunque los pragmatistas clásicos como Dewey estuvieran lejos de compartir ese desdén, sí estaban de acuerdo en que las credenciales del "modo científico" de conocer —entendido ampliamente como un conocimiento sujeto solo a constricciones empíricas y lógicas - no descansaban en construcciones metafísicas de ningún tipo. Dicho de otra manera, para ellos el valor de ese conocimiento, sus pretensiones de racionalidad, eran internas a su propia práctica y no requerían sanción metafísica ulterior.

Ahora bien, con eso no se cancelan las preguntas por el valor o la legitimidad, solo se trasladan a otro ámbito. Aparcada la noción de una Verdad con mayúsculas, trascendente a las operaciones y procedimientos por los que alcanzamos conocimiento efectivo, la cuestión de cómo se instituyen esos procedimientos y operaciones se vuelve crucial y, en el fondo, más difícil de ventilar. La situación a este respecto plantea una paradoja que Dewey explicita en el arranque mismo del Capítulo 1 de su Logic: por un lado, hay acuerdo casi total sobre cuáles son las relaciones formales por las que la verdad de unas afirmaciones permite sostener la verdad de otras, reconocemos "leyes lógicas" que aseguran un tránsito feliz desde proposiciones dignas de ser creídas a otras que también lo serán. Pero, por otro lado, no existe el menor acuerdo — ni a finales del siglo XIX ni a comienzos del XXI, como acabamos de ver- sobre la naturaleza misma de esas leyes que nos permiten construir inferencias y elaborar un discurso que nos enorgullecemos en llamar "racional". Podría decirse que una de las motivaciones fundamentales de la Logic de Dewey es encontrarle una salida a esta situación paradójica.

\section{La confusión del psicologismo}

Más atrás me referí a las seis implicaciones que Dewey enumera como las más destacables de su teoría, una de las cuales era que "las formas lógicas tienen el carácter de postulados". Otra es que "la lógica es autónoma" ${ }^{10}$ Estos dos principios, el de que el régimen de las leyes lógicas es normativo y el de que gozan de autonomía absoluta, son condiciones que, en realidad, cualquier teoría de la

\footnotetext{
${ }^{10}$ La relación completa es la siguiente: "1. La lógica es una disciplina progresiva” (LW, 12, 21); “2. El objeto de la lógica está determinado operacionalmente" (22); “3. Las formas lógicas tienen el carácter de postulados" (23); "4. La lógica es una teoría naturalista” (26); "5. La lógica es una disciplina social” (ibid.); “6. La lógica es autónoma” (28). La segunda implicación ya ha sido aludida antes de pasada, y la discusión que sigue girará fundamentalmente en torno a las cuatro últimas. En cuanto a la primera, que la lógica progresa, es quizá la más provocativa pero también la que mejor apresa el espíritu de toda la obra, porque es inevitable si se aceptan las demás. Ese espíritu, por cierto, Dewey lo toma directamente de Peirce y su idea de que la lógica avanza a impulsos de las mejoras en los métodos de investigación, y no a la inversa: "todo trabajo científico lo bastante importante como para ser recordado por unas pocas generaciones suministra alguna ejemplificación del estado imperfecto del arte de razonar en la época en que fue escrito; y cada gran paso en ciencia ha sido una lección de lógica" (Peirce, 2007, 30) (he modificado la traducción).
} 
lógica debe cumplir independientemente del enfoque filosófico que adopte, pues definen su objeto mismo.

El principio de autonomía, dice Dewey, "excluye el hacer descansar la lógica en presuposiciones y supuestos metafísicos y epistemológicos" (LW, 12, 28). Es prácticamente lo mismo que había dicho Frege, de modo más contundente, en el Prólogo a Las leyes fundamentales de la aritmética de 1893:

Considero que es síntoma seguro de error el que la lógica necesite de la metafísica y la psicología, ciencias estas mismas que precisan de principios lógicos. ¿Cuál es aquí la verdadera base originaria sobre la que todo descansa? ¿O es como en el cuento de Münchhausen, que él mismo se sacaba del pantano tirándose de los pelos? (Frege, 1973, 145-146)

Efectivamente, si para respaldar la validez de las leyes de la lógica necesitáramos apoyarlas en cómo está estructurada la realidad en general, o en las características peculiares de nuestros procesos de pensamiento, y dado que a esa estructura y características llegamos mediante profusas inferencias y no por intuición directa e incontrovertible, el círculo vicioso sería inevitable. De hecho, que no podamos permitirnos círculos viciosos en nuestras inferencias, incluidas las que atañen a la naturaleza de la propia lógica, muestra por sí solo lo que se expresa en este principio.

El principio de autonomía, sin embargo, solo nos obliga a no remitir la validez de la lógica a la que puedan tener las teorías procedentes de otros campos, científicos o filosóficos, pero no nos ahorra la explicación de qué estatus tiene y cuál es su verdadero objeto, es decir, no nos dispensa de buscar una teoría también para la lógica. Porque si alguien dijera: "bien, pero el caso es que las formas y relaciones lógicas están ahi, todos estamos de acuerdo en ellas, así que limitémonos a describirlas", como quien describe un ovni sin entrar a discutir si proviene de Marte o de Plutón, le arrebataríamos a la lógica lo único que no puede perder, a parte de su autonomía: a saber, su carácter normativo. Por eso, el principio de que la lógica es normativa, no descriptiva, es la otra condición que toda candidata a teoría de la lógica debe satisfacer. La idea de unas leyes lógicas "de facto" sería sencillamente contradictoria: si esas leyes se limitaran a describir cómo están conectados los objetos del pensamiento, o los de todo mundo pensable, o los de cualquier lenguaje capaz de referirse a unos u otros, entonces serían inviolables y no podrían regular las inferencias porque estas jamás se apartarían de ellas.

Que la lógica es una Ciencia Normativa lo pensaba ya claramente Peirce, como se ve por el párrafo de la carta a Dewey citado antes o por afirmaciones suyas muy anteriores, como la de que "tanto el mal razonamiento como el bueno son posibles; y este hecho es la base del lado práctico de la lógica" (Peirce, 1887/2007, 59). Y también aquí Frege estaba de acuerdo. Consciente de la ambigüedad que encierra la expresión "ley lógica", escribe en el mismo lugar: 
Ángel Manuel Faerna

John Dewey: hacia una historia natural de la lógica

Es funesto aquí el doble sentido de la palabra 'ley'. En un sentido afirma lo que es, en el otro prescribe lo que debe ser. Solamente en este último sentido pueden ser llamadas las leyes lógicas leyes del pensamiento, al fijar el modo como hay que pensar. (Frege, 1973, 145)

El reo de esta confusión "funesta" entre los dos sentidos era el filósofo Benno Erdmann, al que Frege toma como ejemplo paradigmático del psicologismo en lógica. ${ }^{11} \mathrm{El}$ psicologismo, en efecto, ejercía un peso considerable en la filosofía de la lógica del momento, por eso es muy probable que fuera también el psicologismo lo que Peirce tenía en mente al hablar de aquel "horroroso desperdicio de tiempo, de energías y de pensamientos" por parte de quienes "no comprenden la teoría de la inferencia", y que la "tremenda necesidad" que detectaba "en estos tiempos nuestros" fuera la misma que detectaba Frege: a saber, la de distinguir claramente entre las leyes que afirman lo que es y las que prescriben lo que debe ser. Esto explicaría por qué, aunque la empresa de escribir una historia natural de la lógica a Peirce no le pareciera absurda en absoluto, sí pensara que era inútil e inoportuna: inútil porque semejante historia no podía contribuir a erradicar la confusión, e inoportuna porque lo más probable era que contribuyera a alimentarla.

Decir que las leyes lógicas prescriben o estipulan el modo en que hay que pensar significa que son del mismo tipo que las jurídicas o las morales y no como las naturales. Podemos razonar mal y saltar de la afirmación del consecuente de una implicación a la de su antecedente, violando la ley del modus ponens; pero una piedra no puede caer "mal" saltando por sí sola de una cota inferior a una superior, violando la ley de la gravedad. Ahora bien, esto es lo mismo que decir que las leyes lógicas involucran valores de algún tipo, exactamente igual que las morales y las jurídicas, y eso hace posible, al menos en principio, verlas como la expresión de algún interés o propósito humano. Frege, sin embargo, optó por la vía contraria. Si puso tanto énfasis en el carácter normativo de la lógica fue para combatir el psicologismo, que hacía aparecer sus leyes precisamente bajo la forma de "leyes naturales del pensamiento", pero creyó necesario entonces elevarlas a rango sobrehumano: "quien haya admitido una vez una ley del ser verdad, habrá admitido con ello una ley que prescribe cómo hay que juzgar, donde sea, cuando sea y por quien sea" (Frege, 1973, 142). Para Frege, esto no significaba solo que la verdad de las leyes lógicas es incondicionalmente válida una vez aceptada, sino que es también enteramente independiente de nosotros: "para mí [lo verdadero] es algo objetivo, independiente del emisor de juicios, mientras que para los lógicos psicologistas no lo es" (Frege, 1973, 142).

\footnotetext{
${ }^{11}$ En las páginas del mencionado Prólogo, Frege cita repetidamente su Logische Elementarlehre (cf. Erdmann, 1892) publicada el año anterior y que había logrado una rápida repercusión (fue inmediatamente reseñada por Bosanquet en Mind).
} 
Por supuesto, esto está en las antípodas de la verdad entendida como un título honorífico que los emisores de juicios damos a algunos de ellos, y de cualquier cosa que involucre valores humanos de algún tipo, ${ }^{12}$ pero lo importante a nuestros efectos es que amenaza con convertir en papel mojado el principio de autonomía de la lógica, porque es muy fácil deslizarse desde la reivindicación de un ámbito ideal dotado de leyes propias e intemporales al compromiso ontológico con entidades inteligibles o "esencias"; de hecho, es prácticamente inevitable. ${ }^{13}$ En ese caso, quizá sea verdad que la lógica no necesite de la psicología, pero desde luego quedaría completamente a expensas de la metafísica.

Para deshacer la ilusión de que la apelación a una ley sobrehumana puede dar cuenta de la autoridad incondicional de la lógica y despachar el psicologismo, basta preguntarse en cuál de los dos sentidos de "ley" habría que entender la expresión "ley del ser verdad": ‘ afirma lo que es, en cuyo caso la lógica volvería a ser una ciencia descriptiva en vez de normativa?, ¿o prescribe lo que debe ser, y entonces habrá que seguir preguntando quién o qué prescribe eso? Si hay una superstición en filosofía, es la de creer en el poder mágico de las reificaciones (hasta el punto de que Dewey la bautizó por antonomasia como la "falacia filosófica"). Frege criticaba el psicologismo por la razón correcta, esto es, porque convierte en descripción lo que solo puede ser entendido como un sistema de prescripciones; pero identificó mal las implicaciones de ese error, que para él eran caer en brazos del "subjetivismo", y por eso reificó la "verdad lógica". El subjetivismo psicológico, sin embargo, es pura metafísica, y oponerle argumentos desde la teoría lógica compromete a esta recíprocamente con un "objetivismo" planteado en parecidos términos: los de unos "objetos" lógicos que, de nuevo, solo admiten descripción y reinciden en lo que se estaba criticando.

\footnotetext{
${ }^{12}$ Ciertamente, la "verdad" de las leyes lógicas no es lo mismo que la verdad material de las afirmaciones, que es de lo que hablaba James, pero es el propio Frege quien alimenta aquí la confusión entre validez y verdad al usar la expresión "ley del ser verdad". En todo caso, que la validez no puede establecerse con total independencia de la verdad material es otro de los caballos de batalla de la Logic: "al 'purificarse' de toda mácula experiencial, la lógica se ha vuelto tan formalista que solo se aplica sobre sí misma” (LW, 12, 85). El formalismo es justamente el defecto que, para Dewey, impide ver la interdependencia existente entre lógica y método científico (cf. LW, 12, 372 y ss. y cap. 19) ("Lógica y ciencia natural: forma y materia”).

${ }^{13}$ Frege parece querer evitarlo explícitamente cuando escribe: "yo admito un dominio de lo objetivo no-real, mientras que los lógicos psicologistas consideran lo no-real como subjetivo sin más. Y, no obstante, no se ve claro por qué lo que tiene una existencia independiente del emisor de juicios debe ser real, es decir, debe poder actuar directa o indirectamente sobre los sentidos" (ibid., pp. 142-143). Da la impresión de que la solución es meramente verbal: si uno entiende por "real" únicamente lo que actúa "directa o indirectamente sobre los sentidos", entonces es cierto que Frege no se está comprometiendo con la realidad de las proposiciones (o de los "pensamientos", por usar su propio vocabulario). Pero esa definición de lo que significa "real" es la del psicologista y uno no tiene por qué compartirla. En cambio, que real es cualquier cosa que existe independientemente de nosotros parece una definición igual de legítima, si no más, y de acuerdo con ella Frege estaría afirmando aquí la realidad de lo ideal (de lo "no-real” según el psicologismo), es decir, de los "pensamientos" o de las proposiciones.
} 


\section{El Estado de Derecho (lógico)}

Malo sería que los lógicos tuvieran que esperar a que los metafísicos resuelvan sus disputas antes de tener un objeto claro del que ocuparse, porque la cosa parece ir para largo. Por otro lado, que haya o no una "ley del ser verdad" debería preocupar tanto a los filósofos de la lógica como preocupa el que haya o no una justicia divina a los filósofos del derecho (al menos, si son laicos). Se puede pensar que la hay, desde luego, pero la autoridad normativa de la lógica no constituiría un argumento en su favor ni ganaría nada con ello.

Ahora bien, una cosa es no querer dejarse atrapar en la discusión metafísica entre objetivismo y subjetivismo, y otra pretender que no hay diferencia entre lo objetivo y lo subjetivo. Lo primero es solo una forma de cumplir con el mandato fregeano de que la lógica se mantenga separada de la metafísica no menos que de la psicología, porque la cuestión de si lo real —o una parte de ello— tiene su constitución última en el "sujeto", o viene ya constituido por unos "objetos" que lo trascienden, pertenece a la metafísica. ${ }^{14}$ En cambio, negar que pueda determinarse objetivamente cuándo el tránsito de una afirmación tomada como premisa a otra tomada como conclusión resulta legítimo dejaría a la teoría lógica sin objeto de estudio. Ciertamente, la ventaja del lógico es que quien negara eso tendría que usar la lógica para hacer valer su juicio, lo que automáticamente lo dejaría sin efecto. Esto corrobora una vez más que la lógica es autónoma, sí, pero demuestra también que no carece de presupuestos.

No hay que confundir la autonomía de la lógica con la idea de que esta no necesite dar nada por supuesto. Cuando, en una de las citas reproducidas más arriba, Frege hablaba de "la base originaria sobre la que todo descansa", la imagen hace pensar inmediatamente en un orden que lo sustenta todo sin estar él mismo sustentado por nada. Tales imágenes son traicioneras, porque aunque es verdad que el barón de Münchhausen no puede sacarse del pantano tirándose de los pelos, también lo es que quien quiera que lo saque no puede flotar en el aire, sino que, a su vez, tendrá que apoyar los pies en algún sitio. El objeto de estudio de la lógica es el régimen de normas que garantizan el paso de afirmaciones que llamamos verdaderas a otras que sean dignas del mismo título o que posean el mismo valor. Se asume, pues, que ese valor no lo asignan discrecionalmente las preferencias e inclinaciones de nadie en particular, sino que las normas son objetivas; pero no porque tengan "una existencia independiente del emisor de juicios", cuyos intereses quedarían entonces excluidos por principio, sino porque este reconoce y acepta la fuerza prescriptiva de tales normas a la hora de juzgar, o se somete a su imperio, por así decir. El "imperio de la ley” es una idea familiar en el ámbito jurídico y no significa que la ley jurídica goce de existencia independiente, pero tampoco que el contenido que tenga en cada caso sea subjetivo y dependa de uno

\footnotetext{
${ }^{14}$ Pero, como dije antes, los pragmatistas clásicos no desdeñaban la metafísica. En La experiencia y la naturaleza (1925), Dewey había ensayado una que superara precisamente el dilema objetivismo vs. subjetivismo.
} 
mismo: no depende de la voluntad de uno el estar dentro o fuera de la ley, hay procedimientos objetivos que lo determinan. La lógica, en tanto que sistema objetivo de prescripciones sobre cómo hay que pensar, vendría entonces a ser algo así como la traslación al ámbito del juicio intelectual de un régimen que, en lo social, solemos caracterizar como "Estado de derecho". ${ }^{15}$

En definitiva, si hubiera que sintetizar el punto de vista desde el que Dewey acomete la tarea de construir una teoría para la lógica, podría resumirse en lo siguiente. En primer lugar, es un punto de vista que da por sentada la existencia de una cierta práctica, esa que Frápolli describía como "las actividades inferenciales de los seres humanos de carne y hueso". De no existir tales actividades, la teoría de la lógica no tendría nada que estudiar, así que no es la teoría la que hace posible esa práctica, sino que es solo esta la que nos lleva a preguntarnos por aquella. En este sentido, el punto de vista es pragmatista. En segundo lugar, el punto de vista atiende solo a las operaciones y procedimientos que llevan a revestir los juicios de un determinado valor, hecho que es independiente de consideraciones extra-lógicas como la de si existen al margen de los juicios ciertos "objetos" dotados de ciertas "relaciones intrínsecas" expresables en una "ley del ser verdad". Tanto si se piensa eso como si no, lo que uno hace al inferir es tratar de asegurarse juicios fiables, fidedignos, dignos de confianza; $y$, a la inversa, si la verdad del juicio no viniera indefectiblemente acompañada de ese valor para el emisor, el sentido de la práctica se perdería por completo. La perspectiva, por tanto, también es operacionalista. Y, en tercer lugar, dado que hablamos de seres humanos de carne y hueso, la explicación que alcancemos a dar de cómo llega a instituirse entre las prácticas humanas el "imperio de la ley lógica" debería ser al menos congruente con las explicaciones que demos del resto de nuestra conducta orientada a fines, sin invocar facultades o necesidades ad hoc que justifiquen nuestro "interés en la verdad" como algo irreductible por principio a cualesquiera otros juicios de valor (igual que, para Moore, "bueno" era una propiedad irreductible por principio a cualquier otra que pudiera tener la cosa y que también nos moviera hacia ella). En este sentido, la perspectiva es naturalista además de pragmatista.

Ciertas teorías actuales afrontan la misma tarea en un espíritu solo en parte similar. Robert Brandom, por ejemplo, reclama también el título de pragmatista para sus concepciones semánticas y lógicas. Para Brandom, tanto el contenido semántico de las oraciones como el significado de los términos lógicos vienen definidos por los compromisos inferenciales implícitos que asumimos en su uso. En su perspectiva, la lógica aparece descrita como la explicitación del espacio normativo de nuestra conducta lingüística misma, que se caracterizaría precisamente por situarnos como hablantes bajo obligaciones relativas a qué se sigue de lo que

\footnotetext{
${ }^{15}$ Aunque, de acuerdo con la historia que reconstruye Dewey en su Logic, la genealogía sería más bien la inversa, porque los seres humanos encontraron la manera de reglamentar sus pensamientos en formas objetivadas y racionales antes de que aprendieran a hacerlo con sus interacciones sociales (o, quizá más exactamente, mientras lo hacían).
} 
decimos y de qué se sigue eso que decimos. Expresado en sus propios términos, algo es una aserción cuando es:

[...] susceptible de servir como razón y a la vez de estar potencialmente necesitado de razones. Así, un contenido proposicional es aquello que puede desempeñar el papel tanto de premisa como de conclusión en las inferencias. Conforme a esto, se entiende que la práctica discursiva tiene esencialmente una articulación inferencial. (Brandom, 2011, 30)

De aquí se desprende que la teoría de Brandom está en sintonía con los principios de autonomía y normatividad lógicas que hemos examinado, y que su enfoque efectivamente es pragmatista en la medida en que hace de la práctica del "dar y pedir razones" el fundamento, y no el resultado, de la existencia de lo lógico. El énfasis sobre los compromisos como única "base originaria sobre la que todo descansa" remite a la misma idea de un "Estado lógico de derecho", o al reconocimiento de obligaciones mutuas objetivas, como necesario trasfondo de la posibilidad misma de hacer juicios.

Sin embargo, Brandom también es muy crítico con los esfuerzos de naturalizar la lógica, no ya mediante estrategias descriptivistas como la del psicologismo, sino incluso por el camino de Dewey de establecer continuidades entre los valores que rigen la normatividad del discurso y los que se ponen de manifiesto en el resto de prácticas humanas, naturales y sociales. Él es partidario de un "excepcionalismo normativo" (Brandom, 2011, 55) que, aunque no se abone a postulados ontológicos de ninguna clase, se instala en la radical discontinuidad entre lenguaje y naturaleza y hace de la racionalidad — del "espacio lógico de las razones" - una singularidad total, una especie de burbuja que no parece tocar en ningún punto con el mundo de la vida, por más que la burbuja no contenga otra cosa que prácticas humanas.

El problema que Brandom le encuentra a la idea de que la lógica es una herramienta o un instrumento para investigar es que, si Dewey reconoce que el lenguaje es el recurso capital de la investigación, y a la vez define la investigación como una actividad de resolución de problemas, lo que hace es trasladar los fines de la práctica lingüística al exterior del lenguaje mismo (fuera de los límites de la burbuja, por así decir), lo cual a Brandom le parece contrario a la esencia de la propia práctica:

Aunque está claro que la práctica lingüística nos ayuda a conseguir nuestros fines, la inmensa mayoría de ellos son fines que no podríamos ni tan siquiera concebir, no digamos ya alcanzar, al margen de nuestra participación en la práctica lingüística. Es solo porque sabemos hablar por lo que podemos siquiera querer hacer la mayor parte de las cosas que queremos hacer. La propia inteligibilidad de los fines depende de nuestras capacidades lingüísticas. Justamente no son metas que podamos entender primero, de forma que luego pueda entrar en escena 
el lenguaje desempeñando el papel de una posible herramienta para lograrlas. (Brandom, 2011, 80) $)^{16}$

Claramente, lo que Brandom repudia de Dewey es su instrumentalismo, el nombre que él mismo dio a su filosofía de la lógica y del conocimiento en general; por eso sorprende que sus palabras pasen tan completamente por alto lo que Dewey quería decir con él.

\section{El sentido del instrumentalismo}

Dewey explicó tantas veces el sentido de su instrumentalismo, en tantos lugares y para tantos propósitos distintos, que es más sencillo ilustrarlo mediante un ejemplo que aclararlo mediante citas. Tomemos un caso de instrumentos por antonomasia: los instrumentos musicales. Estaremos de acuerdo en que una flauta sirve para hacer música, es un medio para ese fin y no hay mejor forma de expresarlo. Sin embargo, sería cómico pensar que de ahí se sigue que primero tuvo que existir el deseo o la necesidad de hacer música para que, a continuación, alguien se pusiera a fabricar algún posible instrumento con que hacerla, ya sea una flauta, un tambor o lo que fuere. La propia voz humana es un instrumento musical, seguramente el más antiguo, pero eso tampoco significa que la meta de la música tuviera que preexistir a la idea de emplear la voz como medio para producirla. Entendemos perfectamente que el medio y el fin, el instrumento y su destino, tuvieron que aparecer a la vez, en interacción recíproca. Antes de que hubiera música, desde luego que existían las cañas de madera, los troncos de árbol y la voz humana, pero no había instrumentos musicales; y tampoco hubo instrumentos musicales hasta que no empezó a haber música.

Es fácil imaginar cómo pudo originarse la práctica de la música alguna vez. Alguien, por puro aburrimiento, o accidentalmente, o con cualquier intención que no tenía nada de "musical", golpeó un tronco hueco, o sopló por una caña, o moduló la voz de una determinada manera, y obtuvo un resultado no buscado pero interesante, un sonido que le proporcionaba una experiencia nueva, agradable, que inmediatamente sugería formas posibles de prolongarla, de hacerla accesible a voluntad, de depurarla e intensificarla. Ese alguien estaba inventando simultáneamente la música y los instrumentos musicales; no partió de una meta preconcebida que le pusiera en el camino de buscar los medios para alcanzarla, sino que puso en una relación medio-fin elementos que ya se daban por separado en su experiencia y que, así articulados, le agregaban a esta un determinado valor.

\footnotetext{
${ }^{16}$ Véase todo el epígrafe X (“The Language-as-Tool Metaphor”) del capítulo 2, pp. 77-81. Sobre la concepción que tiene Brandom de "la" práctica lingüística (por contraposición a "las" prácticas en plural que hallamos en Dewey o en Wittgenstein) y lo escasamente pragmatista que resulta esa concepción, he argumentado en otro lugar (cf. Faerna, 2014).
} 
La relación medio-fin, que Dewey identifica con la noción misma de racionalidad tanto en la conducta como en el discurso, ${ }^{17}$ no conecta los términos externa y mecánicamente, sino que la conexión es interna y orgánica. Un instrumento nunca sirve a un propósito que le es previo del todo, sino que él mismo habilita en mayor o menor medida - y a veces completamente, como en el ejemplo que nos ocupa- aquello para lo que es un medio. El caso es el mismo con el lenguaje: sin él no podrían darse fines que solo son concebibles desde la propia práctica lingüística, como bien dice Brandom, pero no por eso deja de ser un medio o instrumento para algo, no algo que simplemente se ejercita a sí mismo. ${ }^{18}$ Eso sería como pensar que una flauta es algo que solo existe para "hacerlo sonar", sin que el resultado revierta en nuestra forma ulterior de soplarla o de fabricarla para que sirva mejor a nuestros propósitos.

Entre una caña o un tronco hueco y una orquesta sinfónica no hay sino un largo camino continuo de ajustes medios-fines que explica a la vez, e inseparablemente, la historia progresiva y conjunta del arte musical y la de los instrumentos musicales. Así también, pensaba Dewey, entre el lenguaje usado como vehículo de comunicación y reproducción cultural — que es su primera explicación biológica y antropológica- y el instrumento inferencialmente articulado que analiza Brandom - que sirve a los propósitos del conocimiento intelectual y de la ciencia- debe de haber igualmente un camino continuo que explique conjuntamente la historia de las prácticas de investigación y la de las formas lógicas que son su instrumento. ${ }^{19}$ Por eso los hábitos de inferencia, la "práctica de dar y pedir razones", que para Brandom es esencial al saber hablar, para Dewey (y para Peirce) era una función cultural sobrevenida de ese saber hablar, como la ejecución musical es una función cultural sobrevenida de los troncos de madera y los cuernos de animales.

Contestando a la última de las preguntas que quedaron planteadas al principio, es posible que hoy la situación filosófica se haya invertido hasta cierto punto y resulte oportuno y útil examinar la lógica en una perspectiva de historia natural. Si en tiempos de Peirce y Frege, los padres de la lógica moderna, los problemas para una correcta comprensión de la naturaleza de las inferencias procedían principalmente del psicologismo, que era ciego a su dimensión normativa, en la actualidad podrían proceder de la carencia opuesta, de un cierto deslumbramiento por la dimensión normativa que impide ver de dónde vienen las normas y para

\footnotetext{
17“ La razonabilidad o racionalidad es una cuestión que tiene que ver con la relación de medios y consecuencias, según la posición aquí adoptada y también según el uso común” (LW, 12, 17). ${ }^{18}$ Esto sugiere un cierto paralelismo entre la posición de fondo de Brandom y la que Dewey reprochaba a los formalistas lógicos, esa que hacía que la lógica solo pudiera aplicarse sobre sí misma.

19"Se diría que les incumbe a los lógicos más que a los demás el hacer coherente su posición en lógica con sus creencias sobre otras materias. Si uno niega lo sobrenatural, entonces tiene la responsabilidad intelectual de indicar cómo puede conectarse lo lógico con lo biológico en un proceso de desarrollo continuo" (LW, 12, 31-32).
} 
qué son buenas. Al fin y al cabo, también algunos filósofos del derecho incurren en un vicio parecido y tienden a hacer del formalismo jurídico la única razón de ser del derecho.

Desde esa perspectiva de historia natural, de la cual la Logic de Dewey sigue siendo el ensayo más ambicioso hasta la fecha, ${ }^{20}$ el discurso lógicamente reglamentado se percibiría como la disciplina social que es, en el doble sentido de la palabra "disciplina": porque estudia un objeto cuya realidad no existe fuera de las prácticas específicamente humanas, y porque entrena o educa a la comunidad de los pensantes en cómo se debe pensar. Lo que nos impone el tipo de relaciones de premisa a conclusión y de razón a consecuencia que damos por legítimas no es la semántica por sí sola, ni unos existentes no-reales que gravitan sobre nosotros; es más sencillo suponer que somos nosotros mismos los que nos disciplinamos porque pensamos que nos hacemos más inteligentes y resolvemos mejor nuestros problemas cuando cumplimos nuestras obligaciones lógicas.

\section{El arte de hacer ciencia}

Dewey había publicado El arte como experiencia en 1934, es decir, solo cuatro años antes que la Logic. De nuevo un grueso volumen (350 páginas esta vez), lleno de ideas igualmente extemporáneas e insólitas para su época pero quizá no tanto para la nuestra. La cercanía temporal en la escritura de dos libros de temática tan opuesta deja de sorprender cuando se leen consecutivamente, porque su temática no es opuesta en absoluto. Entre la investigación científica y la artística él encontraba muchas más convergencias que divergencias, y la mayoría iban en la dirección de aproximar la ciencia y el conocimiento al arte, no a la inversa. ${ }^{21}$ Acabamos de verlo ilustrado con el ejemplo de la música. El instrumentalismo tiende a asociarse siempre con una tosca reivindicación de los valores más ramplones o menos elevados, pero pocas cosas son más elevadas ni pueden elevar más que la música, y sin embargo no hay nada más radicalmente instrumental ni menos separable de sus instrumentos. En el curso de su historia, las prácticas científicas y las artísticas alumbran sus propios valores, llámense la verdad o la belleza, y ninguno de ellos representa algo extrínseco a las prácticas mismas; son el título honorífico que reciben algunos resultados cuando satisfacen lo mejor

\footnotetext{
${ }^{20}$ Ensayo que él estaba muy lejos de dar por definitivo y que presentaba solo como un "método de aproximación" que confiaba en que otros mejoraran: "mis mejores deseos, así como mis esperanzas, son para aquellos que se embarcan en la tarea profundamente importante de poner de acuerdo la teoría lógica con la práctica científica, no importa lo mucho que sus conclusiones puedan diferir en detalle de las que se presentan en este libro" (LW, 12, 5).

${ }^{21}$ En La experiencia y la naturaleza ya había afirmado "que la ciencia es un arte, que el arte es práctica, y que la única distinción que merece la pena hacer no es entre práctica y teoría, sino entre aquellas formas de práctica que no son inteligentes, que no se disfrutan de modo inherente e inmediato, y aquellas que están llenas de significados que se pueden disfrutar" (LW, 1, 269).
} 
posible las expectativas depositadas en sus respectivos instrumentos, que a su vez intentamos mejorar continuamente para hacerlos más dúctiles y eficaces todavía.

\section{Referencias bibliográficas}

Ayer, Alfred J. (1983). Language, Truth, and Logic. Harmondsworth: Penguin Books.

Brandom, Robert. Perspectives on Pragmatism: Classical, Recent, and Contemporary. Cambridge: Harvard University Press.

Colapietro, Vincent (2002). Experimental Logic: Normative Theory or Natural History? En Burke, D. Micah Hester \& R. B. Talisse (eds.), Dewey's Logical Theory. New Studies and Interpretations (pp.43-71). Nashville: Vanderbilt University Press.

Dewey, John (1950). Lógica: teoría de la investigación. México: Fondo de Cultura Económica.

Dewey, John (1989). Cómo pensamos. Barcelona: Paidós.

Dewey, John (1991). Logic: The Theory of Inquiry. En Jo Ann Boydston (ed.), The Later Works of John Dewey (vol. 12). Carbondale and Edwardsville: Southern Illinois University Press.

Dewey, John (2008). Teoría de la valoración. Un debate con el positivismo sobre la dicotomía de hechos y valores. Ma Aurelia Di Berardino y Ángel M. Faerna (Eds.). Madrid: Biblioteca Nueva.

Erdmann, B. (1892). Logik. Bd. 1. Logische Elementarlehre Halle: Niemayer.

Faerna, Ángel M. (2014). On Norms and Social Practices: Brandom, Dewey, and the Demarcation Question. Transactions of the Charles S. Peirce Society, 50(3), 360372.

Frápolli, María José (2017). Reivindicando el proyecto de Frege. La prioridad de las proposiciones y el carácter expresivo de la lógica. Disputatio. Philosophical Research Bulletin, 6(7), 1-42.

Frege, Gottlob (1973). Prólogo a "Las leyes fundamentales de la aritmética". En Estudios sobre semántica. Barcelona: Ariel.

Hickman, Larry (1986). Why Peirce Didn't Like Dewey's Logic? Southwest Philosophy Review, 3, 178-189.

Ketner, K. L. y Cook, J. E. (eds.) (1979). Charles Sanders Peirce: Contributions to the Nation. Vol. 3 (1901-1908), Lubbock, Texas Tech. Press.

Moore, G. E. (1972), ¿Es la bondad una cualidad? En Defensa del sentido común, y otros ensayos, Madrid: Taurus.

Peirce, Charles S. (2007). La fijación de la creencia. En La fijación de la creencia / Cómo aclarar nuestras ideas. Oviedo: KRK. 